\title{
Serosal prolapse through vagina: a rare presentation of uterine perforation following a surgical abortion
}

\author{
Roger Christopher Gill, Hajira Zafar Malik, Fatima Mannan, Aymen Shakeel Mirza and Tabish Umer Chawla
}

Department of General Surgery, The Aga Khan University Hospital Karachi, Pakistan

\section{Introduction}

Surgical abortions are performed routinely across the world. According to recent estimates, 853,000 surgical abortions are performed in the USA annually [1]. Though generally considered as safe procedures, they can have certain complications such as hemorrhage, incomplete abortion, cervical injury, infection and uterine perforation $[2,3]$. A uterine perforation can have varying presentations, ranging from asymptomatic to bowel incarceration. We report a unique case of a young woman presenting with serosal prolapse into the vagina after undergoing Dilatation and Curettage (D\&C) at eleven weeks of gestation for a missed abortion.

\section{Case report}

We report the case of a 21-year-old lady, Para 2+1, presenting to our Emergency Department with severe abdominal pain and tenderness for one day. She had undergone $\mathrm{D} \& \mathrm{C}$ one day ago for a missed miscarriage at a local hospital. Ever since coming out of the General Anesthesia, the patient had been experiencing the abovementioned symptoms. However, no documented findings of the said procedure were available. On clinical examination, the patient was vitally stable. Abdominal examination revealed generalized tenderness, guarding in the lower abdomen and absent gut sounds. On per vaginal examination indiscernible thin, pink, elongated strips of tissue were seen prolapsing from the vagina. The complete length or the point of origin of the tissue could not be determined. Rest of the systemic examination was unremarkable. CT scan performed showed a suspected focal perforation in the uterine fundus with associated pneumoperitoneum and free fluid in pelvis and right iliac fossa (Figures 1-3). No evidence of colonic perforation was seen on CT. Based on the clinical presentation and imaging findings, the patient was planned for an emergency exploratory laparotomy.

Intra-operatively, a perforation measuring less than $1 \mathrm{~cm}$ was noted on the uterine fundus (Figure 4). Upon exploration, no perforation in the large or small bowel was found and mesentery was normal. However, a large portion of ileum measuring up to $270 \mathrm{~cm}$ was stripped of its serosa completely (Figures 5 and 6). This ripped off serosa was seen protruding through the perforation into the uterus. Healthy small bowel with intact serosa was present extending up to $290 \mathrm{~cm}$ proximal and $110 \mathrm{~cm}$ distal to the affected bowel. The uterine perforation was repaired with Vicryl 0 . The $270 \mathrm{~cm}$ of involved ileum was resected and side to side functional end to end anastomosis of the remaining bowel was made.

Post operatively, the patient was transferred to a high dependency unit, where she remained hemodynamically stable and was shifted to general ward on postoperative Day 3. Following an uneventful recovery, she was discharged on postoperative day 6 .

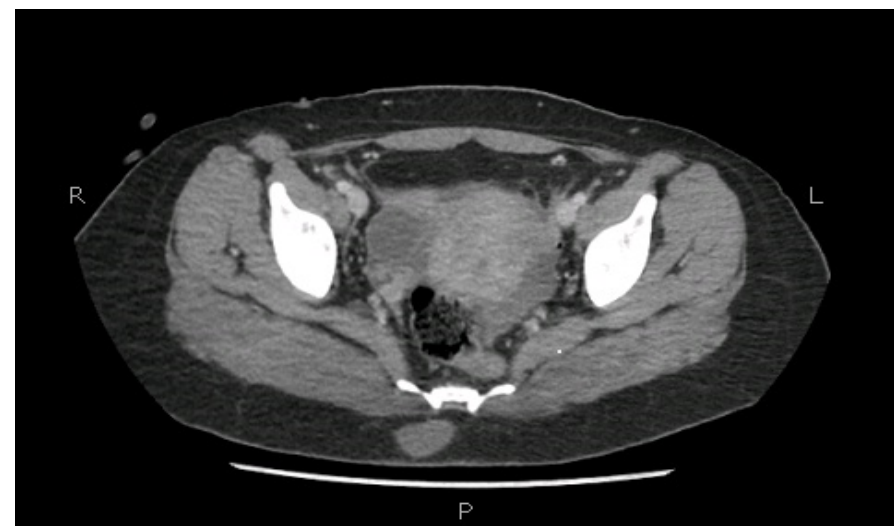

Figure 1. Free fluid within the pelvis, right iliac fossa and extending up to the right paracolic cutter. Minimal free specks of air seen within the peritoneum in pelvis and paraumbilical region

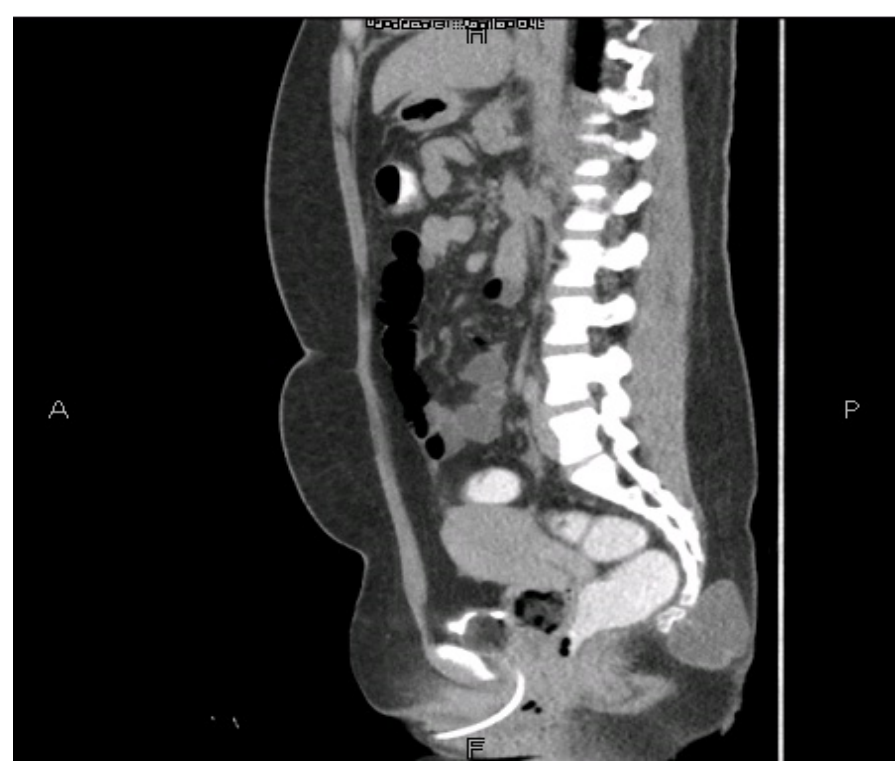

Figure 2. Saggital section showing linear hypoattenuating track in continuation with the endometrial canal and extending up to the fundus and reaching up to the serosal lining representing focal site of perforation

*Correspondence to: Roger Christopher Gill, Trauma Fellow, The Aga Khan University Hospital Karachi, Pakistan, E-mail: roger.gill@aku.edu

Received: May 18, 2018; Accepted: May 28, 2018; Published: May 30, 2018 


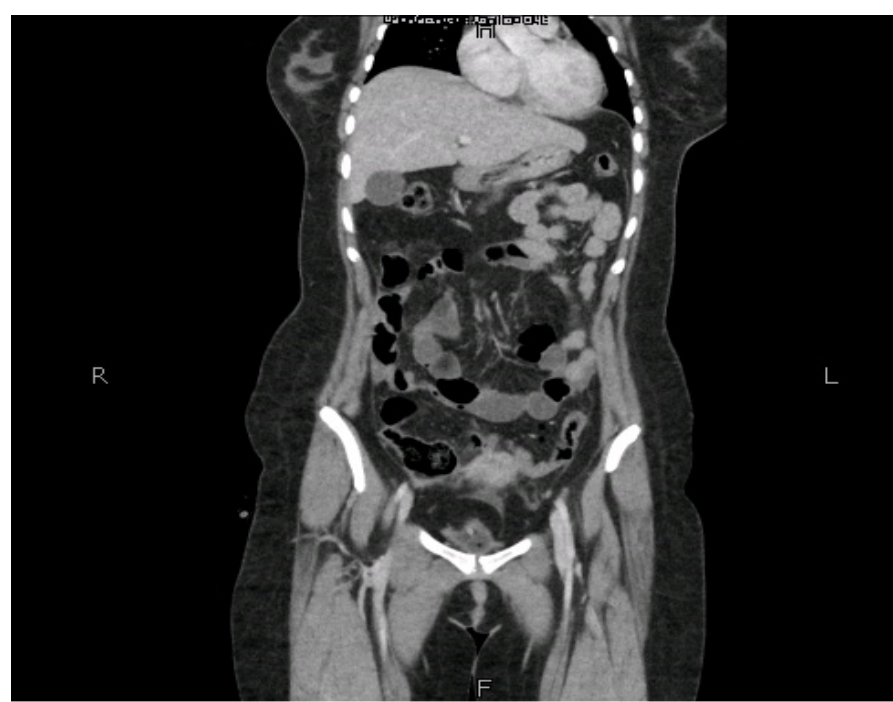

Figure 3. Minimal free specks of air seen within the peritoneum in pelvis and paraumbilical region

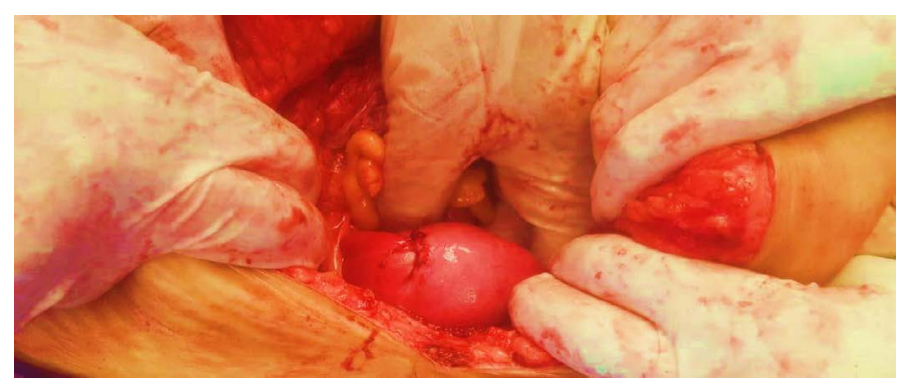

Figure 4. Image showing site of uterine perforation at the fundus through which serosa had been stripped off the small bowel was taken though the uterine cavity seen as prolapsing out of the vagina

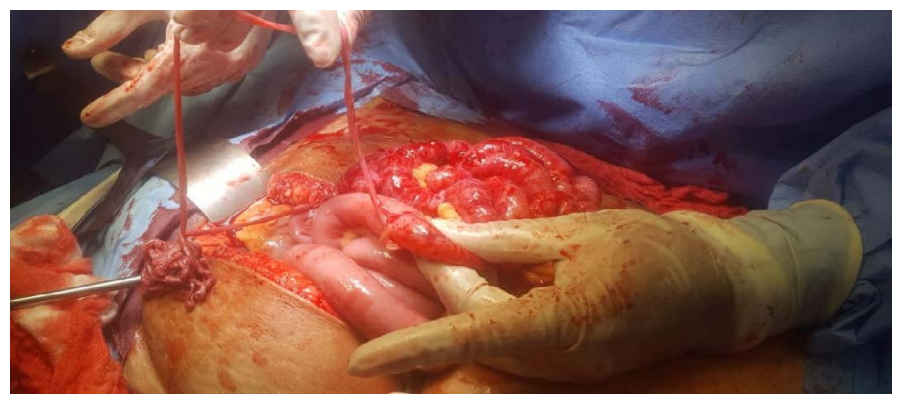

Figure 5. Serosa lifted to show how it appeared like a ribbon. Seen also is a large part of the small bowel devoid of serosal lining

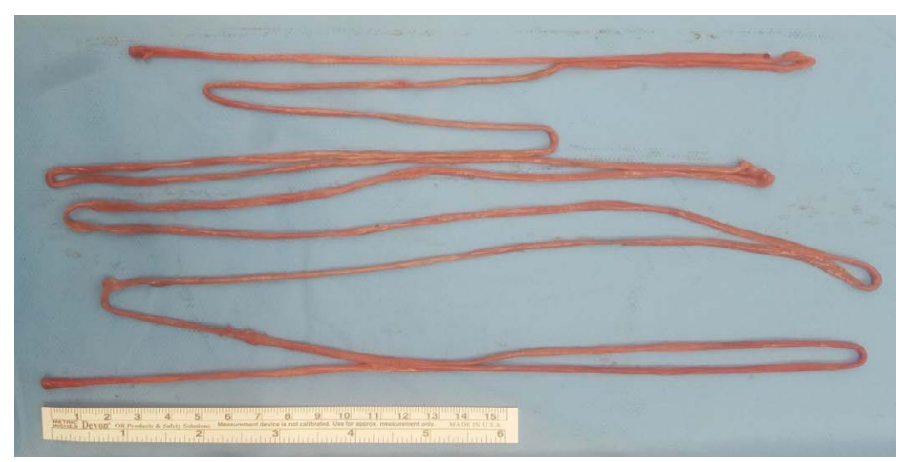

Figure 5. Serosa lifted to show how it appeared like a ribbon. Seen also is a large part of the small bowel devoid of serosal lining

\section{Discussion}

Dilatation and curettage is a routinely performed procedure, done in both inpatient and outpatient setting, worldwide. While considered a relatively risk-free procedure, it has some well-known complications. Some of the early complications are post abortive bleeding, retained products of conception, endometritis, uterine perforation and peritonitis. Late complications may include secondary infertility, ectopic pregnancy and cervical incompetence [4].

Uterine perforation is a rare but documented complication of surgical abortions, with an incidence rate of less than 0.6 percent [5-7]. The single most important risk factor for uterine perforation during Dilatation and Curettage is inexperience of the operator $[4,6,8,9]$. Other risk factors that may contribute to uterine perforation are a retroverted or retroflexed uterus, history of prior cesarean section or abortion, advanced gestational age, infection, cervical stenosis, vaginal atrophy, distorted uterine anatomy and conditions that alter the strength of myometrium like breastfeeding, pregnancy and menopause [5,6,9-11]. Most common site documented in literature for a uterine perforation is the fundus [12].

A uterine perforation is typically and most frequently asymptomatic [12]. However, there is a multitude of clinical presentations of a uterine perforation that have been documented in literature, including small bowel herniation. This can cause intestinal obstruction and incarceration [12]. There have also been instances of mesenteric, appendicular and ovarian herniation through the defect in the uterine wall $[1,13,14]$. A case of omental herniation secondary to uterine perforation, causing strangulation of the intraperitoneal intact small bowel has also been recorded [15]. Another point of note is that uterine perforation during a Dilatation and curettage may have a delayed presentation, leading to errors in diagnosis, unnecessary imaging and suboptimal management [15]. The presentation that we report, however, has not been documented before to the best of our knowledge.

\section{Learning point}

With this case report, we aim to educate the obstetricians of a rare and potentially fatal adverse outcome of a routine procedure. The index of suspicion for uterine perforation should remain high in cases where an unidentifiable tissue is encountered. In such situations, we recommend that the procedure be immediately halted to avoid further damage. In retrospect we feel a large part of the patient's bowel could have been saved had this complication been recognized earlier and the curettage discontinued.

Such a large segment of small bowel devoid completely off its serosa has not been documented. Since it is a rare presentation there were no specific management guidelines. Another possible management strategy that we considered was to decompress the affected bowel and exteriorize the healthy portion until healing takes place. However, due to lack of data to support this strategy we opted for the safer approach of resecting the affected bowel. With this case report, we hope to draw attention to the lack of guidelines regarding the management of a uterine perforation compromising the gut. This report identifies gaps in literature regarding the justification and criteria for preservation versus resection of the injured bowel in such a case.

\section{References}

1. Dignac A, Novellas S, Fournol M, Caramella T, Bafghi A (2008) Incarceration of the appendix complicating a uterine perforation following surgical abortion: $\mathrm{CT}$ aspects. Emerg Radiol 15: 267-9. [Crossref]

2. Soulat C, Gelly M (2006) Immediate complications of surgical abortion. J Gynecol Obstet Biol Reprod (Paris) 35: 157-162. [Crossref] 
3. Ozaki K, Suzuki S (2013) Uterine perforation with omentum incarceration after dilatation and evacuation/curettage. Arch Gynecol Obstet 1: 1-2. [Crossref]

4. Chen L, Lai S, Lee W, Leong N (1995) Uterine perforation during elective first trimester abortions: a 13-year review. Singapore Med J 36: 63-67. [Crossref]

5. Grossman D, Blanchard K, Blumenthal P (2008) Complications after second trimester surgical and medical abortion. Reprod Health Matters 16: 173-182.

6. Amarin ZO, Badria LF (2005) A survey of uterine perforation following dilatation and curettage or evacuation of retained products of conception. Arch Gynecol Obstet 271: 203-206. [Crossref]

7. Ben-Baruch G, Menczer J, Shalev J, Romem Y, Serr DM (1980) Uterine perforation during curettage: perforation rates and postperforation management. Isr J Med Sci 16: 821-824. [Crossref]

8. Ntia I, Ekele B (2000) Bowel prolapse through perforated uterus following induced abortion. West Afr J Med 19: 209-211. [Crossref]

9. Lothe S MK, Warke HS, Satia MN (2015) Uterine Perforation with Omental Incarceration During Suction Evacuation. JPGO 3: 1-100.
10. Jansen FW, Vredevoogd CB, Van Ulzen K, Hermans J, Trimbos JB, et al. (2000) Complications of hysteroscopy: a prospective, multicenter study. Obstet Gynecol 96 266-270. [Crossref]

11. Aydeniz B, Gruber I, Schauf B, Kurek R, Meyer A, et al. (2002) A multicenter survey of complications associated with 21676 operative hysteroscopies. Eur J Obstet Gynecol Reprod Biol 104: 160-164. [Crossref]

12. Coughlin LM, Sparks DA, Chase DM, Smith J (2013) Incarcerated small bowe associated with elective abortion uterine perforation. J Emerg Med 44: e303-e6. [Crossref]

13. Kambiss S, Hibbert M, Macedonia C, Potter M (2000) Uterine perforation resulting in bowel infarction: sharp traumatic bowel and mesenteric injury at the time of pregnancy termination. Mil Med 165: 81-82. [Crossref]

14. Su S, Tao G, Dong B, Shi L, Dong J (2015) Delayed presentation of uterine perforation with ovary migration after dilatation and curettage. Int J Clin Exp Med 8: 6311. [Crossref]

15. Leibner EC (1995) Delayed presentation of uterine perforation. Ann Emerg Med 26: 643-646. [Crossref]

Copyright: $\left({ }^{2} 2018\right.$ Gill RC. This is an open-access article distributed under the terms of the Creative Commons Attribution License, which permits unrestricted use, distribution, and reproduction in any medium, provided the original author and source are credited. 